\title{
Escola Estatal versus Escola Pública: educação, experiências e produção de conhecimento na perspectiva de ocupações de escolas (Uberlândia, MG, 2016) ${ }^{1}$
}

\author{
State School versus Public School: Education, Experiences \\ and Knowledge Production from the Perspective \\ of School Occupations (Uberlândia, MG, 2016)
}

\author{
Sérgio Paulo Morais* \\ Douglas Gonsalves Fávero** \\ Denise Nunes De Sordi***
}

\section{RESUMO}

O artigo busca analisar a experiência social das ocupações de escolas realizadas em Uberlândia (MG) em outubro/novembro de 2016, quando os estudantes secundaristas assumiram a gestão das escolas em protesto contra a PEC 241, a Reforma do Ensino Médio e o programa Escola sem Partido - pautas articuladas com questões locais como a estrutura precária das escolas, a verticalização da gestão escolar e críticas ao modelo de ensino-aprendizagem. Após a recomposição do movimento de ocupações analisa-se a relação colocada para a educação, sobretudo no tocante ao ensino de História. Nota-se que nas dinâmicas de protesto, os estudantes articularam uma nova escola, centrada em diferentes valores e projetos. Portanto, ao expressarem a função social de caráter pú-

\begin{abstract}
The article discusses the social experience of occupations in schools by students in Uberlândia (MG) between October/November of 2016. In this period, high school students took the administration of the schools in protest against the PEC 241, the political reform of the laws about education principles, and the "Escola Sem Partido" program, questions articulated with local problems about the precarious structure of schools, the vertical management of education and critics related to teaching and learning process. We analyze the relationship between students based on the new experiences lived in this process, especially with regard to the teaching of History. During the protests, students organized a new school, centered on different values and projects. Therefore, in expressing
\end{abstract}

\footnotetext{
* Universidade Federal de Uberlândia (UFU), Uberlândia, MG, Brasil. moraissp@yahoo.com.br ** Universidade Federal de Uberlândia (UFU), Uberlândia, MG, Brasil. faverodg@gmail.com *** Universidade Federal de Uberlândia (UFU), Uberlândia, MG, Brasil. denisends@me.com
} 
blico das escolas compuseram um legado futuro para a transformação do ensino e das escolas.

Palavras-chave: ocupações de escolas; experiências; produção de conhecimento. the public social function of the schools, they formed a legacy for the transformation of teaching and schools.

Keywords: occupation of schools; experiences; knowledge production.

Entre os meses de outubro e novembro de 2016, mais de 20 (dentre 34) escolas de Ensino Médio foram ocupadas em Uberlândia (MG). Durante as ocupações realizamos entrevistas com ativistas para compreender como suas pautas se articulavam com questões postas no cenário político nacional, a saber: a Proposta de Emenda Constitucional (PEC) n 241 (no Senado, PEC 55), a Reforma do Ensino Médio e o programa Escola sem Partido, ${ }^{2}$ e como se fundamentavam a partir de suas visões de mundo, expectativas e avaliações sobre a educação. Acreditamos que tais processos interpretativos poderiam ser alcançados pelas narrativas desses próprios atores sociais.

Tal como nos informa Alessandro Portelli, "não só a filosofia vai implícita nos fatos, mas a motivação para narrar consiste precisamente em expressar o significado da experiência através dos fatos [...]" (Portelli, 1996, p. 60). De modo que o ato de narrar "se mede pela capacidade de abrir e delinear o campo das possibilidades expressivas" (Portelli, 1996, p. 65).

As 12 entrevistas produzidas ${ }^{3}$ evidenciaram que as ações políticas das ocupações foram justificadas pela busca do direito à educação e por reivindicações de práticas mais contextualizadas de ensino, que rompessem com o estruturalmente oferecido em termos educacionais em vigor até então. As narrativas articuladas pelos estudantes propiciaram apreender que as mobilizações contestavam as diferenças existentes entre o ensino público almejado por eles (e "prefigurado" por meio de organização de aulões, palestras e atividades autogeridas - Ortellado, 2016, p. 13) e o ensino estatal (Marx, 2004), fornecido e regulamentado pelo "Estado em sentido restrito" (Gramsci, 2000).

Essa avaliação, entretanto, não surgiu de forma direta, ou seja, não se expressou de modo textual e coerente nas entrevistas. Foi necessário avaliarmos diversas temáticas, postas nas falas dos entrevistados, para conseguirmos chegar a essa estrita conclusão. Neste artigo abordaremos alguns elementos apresentados nas falas de entrevistados para discutirmos percepções sobre educação, escola e ensino, no contexto da formação para o trabalho. 
Trataremos de ações internas ocorridas nas ocupações de escola. Sustentamos que nesses eventos ocorreram aprendizagens geradas no âmbito do próprio movimento. Portanto, consideramos, tal como na visão de Maria da Glória Gohn (2011),

uma concepção ampla de educação. Um dos exemplos de outros espaços educativos é a participação social em movimentos e ações coletivas, o que gera aprendizagens e saberes. Há um caráter educativo nas práticas que se desenrolam no ato de participar, tanto para os membros da sociedade civil, como para a sociedade mais geral, e também para os órgãos públicos envolvidos - quando há negociações, diálogos ou confrontos (Gohn, 2011, p. 333)

Mesmo compreendendo não ter havido reivindicações para adoção de projetos educacionais alternativos ao ensino formal, a segunda parte do artigo explora atos educativos produzidos nas ocupações em interface ao ensino formal de humanidades (com destaque para o ensino de História), por constarem tais relações em diversas entrevistas. Não tivemos a intenção de adentrar metodologias particulares e, menos ainda, comparar conhecimentos advindos de experiências e do ato de ocupação com o que era produzido nas/pelas formalidades do ensino. $\mathrm{O}$ fato de ser um movimento social realizado em escolas, sob agência de discentes do ensino médio, levou nossa investigação para tais ambiências do contexto histórico nas quais mudanças radicais (em relação ao direito à escola) foram anunciadas.

\section{DA ESCOLA QUE SE TEM À ESCOLA QUE SE QUER}

No processo de ocupação formaram-se diversas comissões que garantiram a limpeza, a alimentação, a segurança, o diálogo com a imprensa e a realização de atividades didáticas nas escolas. Junto a isso, ocorreu a realização de assembleias para decisões gerais e para discussões sobre o dia a dia (Morais, 2018, p. 181).

Observamos que ao assumirem os alunos a responsabilidade pelo funcionamento e preservação das escolas, problemas antes tratados na esfera das relações institucionais foram ressignificados numa perspectiva crítica: "a gente às vezes acha que a culpa é dos professores, agora que a gente tem acesso direto 
do que acontece com a organização, do que acontece, a gente tá vendo que a organização toda é falha, toda!” (Alice, 2016).

O mesmo se notou para as estruturações físicas das escolas, não mais apontadas como questões meramente secundárias, mas enquanto relação instituinte do ambiente social: os protestos, ao gerarem debates e reflexões coletivas, estruturaram críticas ao ambiente escolar.

Ao possibilitarem avaliações sobre a escola fornecida pelo Estado, tais análises foram verbalizadas de diferentes maneiras, tais como: “aí, agora a gente tá vivendo assim as coisas que o povo da escola faz e a gente tá vendo o tanto que é pesado pra eles, o salário deles é muito baixo, não é? Para eles fazer isso tudo" (Carla, 2016). "Fica gente sentado na porta! É lotado de aluno! Lotado! Os professores não têm material! A gente tem uma sala de informática que não tem [uso e equipamentos funcionando]! (Alice, 2016)"; "a cor, as grades que foram postas em toda a escola, [...] toda a cor da escola... é feia a escola, em si é tudo preto e branco" (Tiago, 2016), "Bom, a estrutura da escola, horrível, não é?” (Carla, 2016); a ausência de diálogo: "É, eles têm que conversar, entendeu? Eles não conversam aqui, eles não explicam nada" (Lucas, 2016); de espaços para sua participação nas decisões: "uma escola que a gente pudesse dar a nossa opinião sem ser julgado [entendeu?], eu acho certo, por exemplo, conversar, porque nada que uma conversa não resolva [...]" (Lucas, 2016).

Outro aspecto que dissociava a educação pública desejada da escola fornecida pelo Estado relacionava-se à proibição do uso de utensílios e espaços que deveriam ser comuns a todos: "Por exemplo, a biblioteca a gente não pode ir lá! [...] quando a gente quer pegar livro na biblioteca tem que marcar o dia pra cê tá indo lá, pra pegar o livro, é uma burocracia danada! Pro cê pegar o seu primeiro livro cê tem que fazer a doação de gibi...” (Carla, 2016).

Nas escolas localizadas nas regiões periféricas chamou-nos atenção a crítica a gestores por não apoiarem estudantes trabalhadores, impedindo sistematicamente a oferta de organização ou flexibilização de seus horários:

Aí eu comecei a trabalhar e meu horário não batia, aí eu passei pra noite, e a noite é horrível, a noite o ensino é péssimo! A coisa mais horrorosa do mundo! [...] "não, não vai dar pra estudar nessa porcaria não", aí eu voltei pro René [escola na região central], e o René não dá pra mim, porque lá demanda um tempo pra estudar, de verdade, e... eu falei "não, não tem como eu estudar nessa escola", aí eu 
voltei, aí eu voltei, eu acho o seguinte, eu saí da manhã e fui pra noite de novo, só que aí não dava tempo, eu pedi pra ela me liberar uns vinte minutos [...] aí ela falou "não, a Alice é repetente, ela tem que estudar a noite". (Alice, 2016)

Tal dimensão da organização escolar nos remete ao debatido por Arroyo (2013) em relação às ausências que são aceitas na organização dos currículos, mas emergem na práxis educacional. Nesse sentido, noções a respeito da organização de seus próprios itinerários de vida, como expressado por Alice, apontam para a contraposição, ou até mesmo denúncia, das desigualdades suportadas pela organização escolar que não os valoriza como agentes do processo educativo.

A narrativa articulada pela estudante evidencia que as escolas se pautam em torno de "tipos ideais" de estudantes, com "propostas que estão extremamente fora da realidade" de suas vidas (Fenelon, 2008, p. 28). Os entrevistados evidenciaram ser preciso considerar, na linha do que debate Arroyo (2007, p. 39), que "as lógicas do ordenamento curricular supõem sujeitos livres para optar pelos valores do estudo, do conhecimento, da assiduidade; não supõem sujeitos sem alternativas de escolhas".

As elaborações apresentadas pelos estudantes nas entrevistas em torno do tipo de "escola que se tem e a que se quer" permitiu-nos evidenciar "que qualquer momento histórico é ao mesmo tempo resultado de processos anteriores e um índice na direção de seu fluxo futuro". (Thompson, 1981, p. 58).

A partir de 1990, diversos experimentos e reformas do ensino foram realizados com mínima participação de docentes e absolutamente nenhuma atuação dos discentes e de outros trabalhadores da educação. Isso se tornou bastante comum nas demais reformas da Educação, percebidas como estreita formação para o mundo do trabalho, com diretrizes advindas de forças e de grupos internacionais (Cerri, 2004). Desse modo, o formato curricular posto nas redes estaduais de ensino, criticado pelos estudantes durante os protestos, tendiam radicalmente ao tecnicismo, voltado para o trabalho social abstrato (Marx, 2017, p. 120-124), distanciando-os daqueles que poderiam pagar por um ensino médio universalizado (Motta; Frigotto, 2017).

A nosso ver, esse é ainda um paradigma importante para a análise global da situação do ensino, das escolas e da educação formal no Brasil. Algo que une a relação de domínio, função e modo de organização das escolas do Estado 
ao que se espera dos egressos do Ensino Médio que adentrarão o mercado de trabalho (Motta; Frigotto, 2017).

Percebe-se que as ocupações denunciaram tais hierarquias por meio da crítica, entre outras, do engessamento curricular organizado por "especialistas" que, em nome da gestão do Ensino Médio, buscaram implementar, tão somente, a formação para o trabalho. A respeito disso, Castoriadis e Cohn-Bendit analisam que

a ciência e a técnica estão muito essencialmente inseridas, inscritas, enraizadas em uma instituição dada da sociedade. Da mesma forma que a ciência e a técnica da época contemporânea nada têm de trans-histórica, não têm valor que esteja para além de toda interrogação, que pertencem ao contrário a esta instituição social histórica que é o capitalismo tal como nasceu no Ocidente há alguns séculos. (Castoriadis; Cohn-Bendit, 1981, p. 13)

A "apresentação da ciência e da técnica como meios neutros ou como puros e simples instrumentos não é simples 'ilusão': ela faz parte, precisamente, da instituição contemporânea da sociedade" (Castoriadis; Cohn-Bendit, 1981, p. 13). Tal perspectiva, fundada no atual capitalismo (mercado) brasileiro, organiza a concepção de escola de Estado e sua relação com o capital (Motta; Frigotto, 2017).

Nesse aspecto, há que se considerar as intenções inerentes ao planejamento e ao currículo nas diversas dimensões do social, sobretudo no que se dissimula em seu conteúdo "oculto" - ou modos de se disseminar a tecnificação do ensino - fator necessário à vida e ao comportamento na sociedade capitalista que nos rodeia (Apple, 1982). A respeito disso, é bastante conhecida a fórmula paradoxal em que os currículos são apresentados (e cobrados) dos professores: "O professor é submetido, na recepção [de] documentos, a uma comunicação que no aspecto verbal e democrático é autonomizadora, crítica e flexível, mas no ato de impor-se como 'verdade pedagógica' desconfirma o docente, reduzindo-o a mero executor [...] de seu próprio ofício” (Cerri, 2004, p. 217).

Assim, sobre o "professor[ado], inicialmente, essas políticas acentuaram uma postura, nas instâncias burocráticas, de desconfiança, desprestígio e disposição de vigilância e direcionamento dele e de seu trabalho", naquilo que alguns intelectuais apontam para "programas à prova de professor", "pensados para serem implementados apesar do corpo docente" (Cerri, 2004, p. 216), mas 
que não limitam resistências ou adequações quando analisadas no interior das relações escolares.

Algumas análises realizadas em períodos recentes têm demostrado que a tecnicidade e adequação ao mundo do trabalho, na condição de empregados dinâmicos e flexíveis, implicam, no conteúdo escolar, ensinamentos adequados ao mundo globalizado. Os Parâmetros Curriculares Nacionais (Peixoto, 2015, p. 55), ainda não totalmente suplantados à época das ocupações, induzem a utilização e a compreensão de várias tecnologias, algo que parece determinante aos operários e ao atual mundo do trabalho.

Em relação às ciências humanas, sobretudo no Ensino Médio (Parâmetros Curriculares Nacionais para o Ensino Médio - PCNEM), esse "fetiche" (tecnologias) "expressa a atribuição de uma função utilitária". Nesse sentido, "predominam assuntos relativos a resultado da ação" das Humanidades "para a melhoria do mundo do trabalho (gestão de indivíduos e dos grupos, planejamento, obtenção e organização de informações, assim por diante)" (Cerri, 2004, p. 221). Desse modo, as "competências como metas", postas nos "Parâmetros", de acordo com Luis Fernando Cerri indicavam que

essa disposição poderia fazer-nos imaginar alguma semelhança com as reformas curriculares [...] marcadas pelo liberalismo da velha Inglaterra em meados da década de 1980, em que [...] permitiam ao professor utilizar qualquer metodologia ou conteúdo, desde que essas metas fossem atingidas. Os PCN, entretanto, [...] são bem mais prescritivos. Mas é importante registrar o posicionamento de que as competências não são construídas na escola, mas sim nas situações reais de vida e trabalho, uma vez que a "pedagogia das competências" tem dificuldades em compreender as especificidades do conhecimento tácito em relação ao conhecimento formal e organizado da escola. (Cerri, 2004, p. 222)

Tal distinção, corroborada pela Lei de Diretrizes e Bases da Educação de 1996 (LDB), Diretrizes Curriculares Nacionais para o Ensino Médio (DCNEM) - Resolução n. 3/98 do Conselho Nacional de Educação - e por uma "cultura de avaliação" na qual os resultados foram articulados para cumprir normativas do Banco Mundial por "meio da redução das repetências" (Zibas, 2005), se encontravam presentes nas interpretações de estudantes que ocupavam as escolas. 
Eu acho que eles deviam pensar que... a gente não é só força de trabalho, entendeu? A galera da escola pensa "ah! Eu vou sair da escola eu não vou estudar mais". Não, tem gente aqui que pensa que não é só força de trabalho a gente precisa de mais coisa que isso. É, vim aqui ter aula de matemática e português e uma de sociologia por semana não é o que a gente precisa, entendeu? Principalmente por ser periferia acho que eles deveriam pensar mais na galera. [...] a maioria dos ricos eles [...] são todos muito bem organizados [...] se a gente não tiver sabedoria, se a gente não se juntar também, a gente não vai poder fazer nada contra isso [...]. (Carla, 2016)

Em relação ao que consideravam ser "qualidade" das aulas, ocorreram diversas pontuações nas entrevistas realizadas, tais como: "eu fico triste com a forma que os professores são tratados, como o aluno é tratado [...] A escola pública tá correndo contra o tempo porque tal professor faz tantos horários por semana, ele não tem tempo [...] é tudo na correria" (Melina, 2016).

Raras foram as críticas pontuais em relação a determinados profissionais do ensino. Os entrevistados, diferentemente disso, encontravam em professores referenciais de saber escolar e de vida. Além disso, alguns demostram vontade de ingressar em mesma profissão. No caso abaixo, professores de história foram citados como exemplos a serem futuramente seguidos.

Olha, eu acho assim, eu tenho, eu tive alguns professores que eu me recordo muito deles e que eles fizeram a diferença pra mim, na forma como eles repassavam o conhecimento. Eu num sei ao certo, como isso pode afetar a vida de uma pessoa, mas eu sei que os meus professores de História, dois, são três professores que eu tenho como exemplo e dois deles são de História. E... eu sei que a forma como eles ensinaram e a forma como eles me passaram, independente de quando ou como eu vou usar, serviu pra alguma coisa porque foi inspirador pra mim e, eu quis cursar História no final de tudo isso e acho que graças a eles também. E, sendo professora de História, por exemplo, eu posso mostrar o lado das coisas, por exemplo, aqui a gente vê o outro lado da História, porque antes é... eu achava, entrando, eu vou abrir um pouco com você, abrir um parêntese um pouquinho, o assunto. Um exemplo, eu achava que a mídia não era tão é... como se diz, manipuladora, eu achava assim "nossa o pessoal exagera quando fala que a mídia é... manipula e essas coisas", só que estando de um lado da História que a mídia não mostra e distorce. Eu vejo que existe uma manipulação muito grande e... eu 
quero mostrar pros meus [futuros] alunos esse lado! Eu quero mostrar que existem dois lados e que a gente também não pode acreditar em qualquer coisa que a gente vê sabe? E eu quero passar isso pra eles, isso entra também aquela questão do Escola Sem Partido, cara! Como é que você vai mostrar a história em si, sem... sei lá, cara! Você precisa mostrar... a história ao longo dos anos, ela é uma questão política. Então, você precisa mostrar isso para as pessoas, e... não sei! Não sei como eles pensam em tirar isso dos outros porque é uma coisa essencial, você precisa saber, sabe? (Juliana, 2016)

Nota-se na fala de Juliana que o papel primordial da educação se revelou no processo de autonomia engendrada na prática. Especificamente no tocante ao ensino de história, que é essencialmente formativo (Fonseca, 2003, p. 11), a articulação entre teoria e prática se revela nas formas da construção para a cidadania e a democracia a partir da formação de instrumentos que permitem a análise dos fatos e o desenvolvimento da consciência crítica.

Questionamos os estudantes sobre como seria a "escola ideal" que deveria surgir após as experiências das ocupações. As respostas obtidas por meio das entrevistas apresentaram interessantes propostas em torno de se ter uma "escola [que] devia liberar pra gente uma forma de pensar mais aberta, eu acho que devia liberar mais debate, [...] eu acho que a tarde deveria ter aula de reforço, eles deveriam abrir pra gente vir e participar [...]" (Alice, 2016); uma escola "onde a gente também tivesse voz, onde as pessoas também tivessem abertos pra poder escutar o que a gente tem a dizer [...]" (Carla, 2016). Com outras regras de utilização dos espaços: “A gente estava até conversando com o diretor e o vice-diretor pra depois que acabasse a ocupação vê se eles libera o sábado e o domingo pra gente fica aqui na escola, não é? Porque, tipo, é legal ficar aqui, a gente não tá achando ruim" (Lucas, 2016).

No processo de ocupação, a necessidade de organizar e gerir as escolas criou "possibilidades compartilhadas" ao exercício do protagonismo dos estudantes para a organização escolar; currículos formais não foram utilizados, a estrutura metodológica do ensino foi autogerida, ambientes antes vazios ou até então de acesso proibido (bibliotecas, laboratórios, salas de direção e professores) foram ocupados (Fávero et al., 2018). Observou-se, portanto, a emergência de diferentes ações autônomas que se distanciaram das regras do Estado e do currículo formal. 
Nas entrevistas realizadas e nas evidências que trataram de ocupações anteriormente ocorridas, sobretudo no ano de 2015, as questões relacionadas à organização curricular apresentaram-se de modo latente (postas na prática do dia a dia), porém, não foram sistematizadas em formato de textos coletivos ou de manifestos por outra escola e por outra educação. Entretanto, a partir da experiência em promover discussões sobre temas que consideraram relevantes, emergiram experimentos alternativos de aprendizagem:

A gente aprendeu uma coisa sobre agroecologia, essas coisas tá tendo aulão diferente, sobre... o poder judiciário, o executivo, o legislativo, a gente tá aprendendo essas coisas agora! Porque os professores mesmo dentro da sala de aula eles não explicam essas coisas. Aí a gente fica tipo como pessoas alienadas, só aprende a mesma coisa. Eu acho que deveria ter isso mais na escola. (Carla, 2016)

Quanto às oficinas,

Eu tô vendo uma diferença muito grande entre as aulas que a gente tá tendo agora, que a gente chama das oficinas, e as normais. Por exemplo, as normais têm o que? Quarenta e cinco? E aqui a gente tem mais ou menos uma hora e vinte de aula e não é cansativo [...]. É uma aula dinâmica, é uma aula que o aluno é, ele, ele pode, ele tem abertura pra poder conversar com o professor sobre o que tá sendo dado pra, pra perguntar sabe? É, totalmente diferente! É totalmente diferente, e o professor, ele tá se sentindo motivado também, pra dar aula. E, num tem bagunça também, sabe? É uma outra coisa, porque não é aquela coisa cansativa, maçante. (Melina, 2016)

Destaca-se como Carla e Melina, a partir de suas experiências nas ocupações, articularam problematizações que há muito têm sido investigadas por especialistas que se dedicam ao tema da organização curricular. Arroyo (2013, p. 43) pontua que: "não é tanto o currículo que está em disputa, mas a docência, o trabalho, a liberdade criativa dos trabalhadores na educação. Está em disputa o conhecimento, a cultura e sua rica diversidade”.

Portanto, as ocupações, além de combaterem diretamente as mudanças que se avizinhavam (pautas políticas do ano de 2016), promoveram reflexões sobre a forma de organização de currículos e de poderes entre os muros das escolas. Contudo, as relações vivenciadas nas atribuições políticas transpuseram as 
vivências localizadas no contexto "chão da escola", ao lançar pendularmente o papel do estudo e da aprendizagem para diversas dimensões sociais. A nosso ver, isso somente pode ser elaborado com experiências sociais mais ampliadas, por meio de aspectos culturais externos (Willis, 1991) e pelo próprio ensino escolar vivenciado.

\section{EXPERIÊNCIA SOCIAL E ENSINO DE HISTÓRIA NO CONTEXTO DAS OCUPAÇÕES}

Adaptar-se para sobreviver, em vez de compreender para transformar. O "fim da História" orienta o ensino de História e das Humanidades para o texto dos PCNEM, e nesse sentido é interessante perguntar até que ponto os conteúdos de História são realmente históricos, no sentido de permitirem pensar o significado dos fatos, oferecendo signos fixos e constantes que neutralizam toda contradição possível entre o que está dado e o que pode surgir historicamente, ditando então normas fechadas para ação e progresso. (Cerri, 2004, p. 222)

No tópico anterior, por meio de entrevistas com ocupantes, buscamos mostrar interpretações sobre o contexto escolar e sobre as relações de ensino-aprendizagem contra as quais incidiram diversas práticas instituintes (aulões, palestras, atividades lúdicas etc.). Vimos que a educação voltada ao trabalho, normatizada pela gestão escolar do Estado, impossibilita mudanças profundas e democráticas nos currículos e práticas escolares. A situação vivenciada em termos de "ensino de História e das Humanidades" equiparava-se, em nossa pesquisa, ao que Cerri (2004, p. 222) indicou como adaptação para sobrevivência.

A nosso ver, a escola tem um papel centralizador das disputas ideológicas e comunga com as possíveis transformações sociais. Como notou Selva Guimarães Fonseca ao analisar as transformações curriculares para o ensino de história ocorridas no período pós-68, essa disciplina escolar afirma "sua importância como estratégia política do Estado, como instrumento de dominação, porque capaz de manipular dados que são variáveis importantes na correlação de forças e capaz de uma intervenção direta no social, por meio do trabalho com a memória coletiva" (Fonseca, 2003, p. 24). 
Porém, imagináveis mudanças no ensino e na aprendizagem demandam (e demandarão) esforços sociais amplos, advindos de fora para dentro do contexto escolar. De modo geral, os profissionais da educação postos em um abissal processo de proletarização (Ferreira, 2006, p. 238), sob os auspícios de uma cultura sistêmica de avaliações (Zibas, 2005, p. 1077), vivenciam longas rotinas de trabalho, baixos salários e aumento quantitativo das atividades extraclasse. Como debate Arroyo (2013, p. 102): "quando os educandos são reduzidos a empregáveis, a docência transforma-se em treinamento".

Nesse sentido, faz-se necessário assumir que a escola é constituída e é, ao mesmo tempo, constituinte do social. Ou seja, pertence e participa da totalidade das relações, dos conflitos, de ambiências e da construção de consciência histórica sobre o país. Isso ocorre como resultado da "simultaneidade da manifestação de relações produtivas particulares em todos os sistemas e áreas da vida social" (Thompson, 2012. p. 254).

Enquanto fator educativo, observamos que as ocupações permitiram a concepção de novos processos de socialização "a partir da materialidade histórico-social em que eles acontecem” (Martins, 2014, p. 305). Assim, a categoria experiência proposta por Thompson (1981) tomou centralidade na análise de nossa pesquisa:

Deste modo, Thompson fornece elementos para pensar os processos de socialização a partir da experiência de homens e mulheres concretos. Distanciando-se de uma perspectiva que vê a socialização como um processo educativo em que os indivíduos apenas receberiam valores, normas, regras, formas de comportamentos ou que afirma a socialização apenas como inculcação ideológica, Thompson, por meio da categoria experiência, fornece elementos para analisar a socialização a partir da dialética entre ser social e consciência social e o agir dos sujeitos nos processos educativos em que se encontram inseridos. (Martins, 2014, p. 314)

Assim, as ocupações de escolas guardaram significativas contribuições para o processo educacional e para a crítica do contexto escolar, ao assimilar, produzir e compartilhar experiências sociais. Estas, E. P. Thompson (1981) entendeu serem "a resposta mental e emocional, seja de um indivíduo ou de um grupo social, a muitos acontecimentos inter-relacionados [...]" (Thompson, 1981, p. 15).

No contexto escolar, a experiência 
modifica, às vezes de maneira sutil e às vezes mais radicalmente, todo o processo educacional; influencia os métodos de ensino, a seleção e o aperfeiçoamento dos mestres e o currículo, podendo até mesmo revelar pontos fracos ou omissões nas disciplinas acadêmicas tradicionais e levar à elaboração de novas áreas de estudo. (Thompson, 2002, p. 13)

Na perspectiva de Thompson (1981), a experiência social é, então, um termo intermediário entre ser social e consciência social, e conduz à elaboração de processos educativos nos contextos em que os sujeitos sociais se encontram (Thompson, 2002), nas contradições do processo histórico constituído. Nesse ponto de vista, a defesa da escola e de um Ensino Médio humanista se evidencia enquanto processo de oposição às expropriações das classes populares em um quadro no qual diferentes reformas e induções legislativas têm demarcado um Ensino Médio dual: propedêutico para as categorias mais ricas e técnico, ou voltado à recriação de trabalhadores, para as categorias mais pobres.

Para compreendermos os perímetros alcançados pelo movimento de ocupações precisamos considerar a permanência de práticas autoritárias advindas ainda do período ditatorial. ${ }^{4}$ Naqueles anos, reformas de ordem curricular, doutrinação religiosa e cívica imprimiram condutas esperadas aos filhos da classe trabalhadora. Hoje essas ilusões estão presentes e se somam à noção de "fim da história" (Cerri, 2004, p. 222) por meio de projetos tais como Escola Sem Partido. Nesse aspecto, as ocupações de escolas e outros movimentos que se deslaçaram pelo enredo das cidades (da reprodução da vida), buscaram restituir "bens comuns", que, de acordo com David Harvey, indicam "profundas continuidades de batalhas de muito tempo atrás” (Harvey, 2012).

Sobre isso, Raquel Rolnik (2015), ao se expressar sobre as recentes manifestações ocorridas no país, afirmou que

Esse terremoto fez emergir não uma, mas uma infinidade de agendas mal resolvidas, contradições e paradoxos. No campo imediato da política, o sismo revelou fissuras na perversa aliança entre, por um lado, o que há de mais atrasado, excludente e prepotente no Brasil e, por outro, os impulsos de mudanças que conduziram o país na luta contra a ditadura e no processo de redemocratização: uma aliança que tem bloqueado o desenvolvimento de um Brasil não apenas próspero, mas também cidadão. (Rolnik, 2015, p. 375) 
O repertório de oposição posto pelas ocupações de escolas se deu por contestação às intervenções no orçamento, à reforma do Ensino Médio e à Escola Sem Partido. Mas o movimento de permanência nos espaços permitiu que ações concretas avançassem na constituição de uma "política de protótipo" (Souza, 2018) democrático, transpondo a estatização do que deveria ser, antes de tudo, público. Nesse sentido, a elaboração de atividades e a vivência política dos estudantes afastaram-se "das noções que tratam a experiência como sinônimo de empirismo, pragmatismo ou como aprender pela experiência tão presentes nas práticas pedagógicas atuais" (Martins, 2014, p. 315). Mas deram indícios de que outros atores sociais, "engendrados no processo histórico" (Martins, 2014, p. 315), contribuiriam com o saber e com a produção social do conhecimento.

Desse modo, mesmo que indiretamente, se contrapuseram à produção técnica curricular "posta de cima para baixo" e se colocaram, mesmo que no interior das instituições e no tempo das ocupações, contra a "fragmentação escolar do sujeito". Restaurando uma noção mais ampliada "do estudo da história", buscando elementos que pudessem torná-la mais "relevante para as pessoas comuns" (Editorial..., 1976). Potencialmente, a educação elaborada pelo movimento faz voltar à cena noções de uma história de agência e de ação humana, que, além de estudada por uma perspectiva dos "de baixo" (Sharpe, 1992), faz-se mais próxima daqueles que procuram marcar nas escolas uma consciência histórica mais democrática (Kaye, 1995).

Assim, questões de gênero, luta contra o preconceito racial, afirmações de identidades e outros estiveram presentes e foram tematizados e reelaborados enquanto prática educacional informalizada, dentro do ambiente formal (Ricci, 2018). As ocupações reforçaram a noção de que "cada geração política é interpelada por um conjunto de urgências, de problemas incontornáveis, e é a partir dessa confrontação, presente nos processos de acirramento, que as gerações vão formulando suas questões e se relacionando com as experiências anteriores" (Souza, 2018, p. 6).

Nas narrativas de ocupantes, registraram-se indicações do que esperavam ser práticas mais contextualizadas e humanizadas de aprendizagem. Veja-se, neste exemplo, a menção ao ensino de História: 
No meu ponto de vista, como uma coisa diferente que podia acontecer com os alunos era visitas diariamente em instituições de ensino. Por exemplo, [...] o professor de história [...] a cidadezinha chamada Martinésia [...] tem um antigo quilombo [...]. Como temos o conhecimento da escravidão daquela época, vamos levar os alunos lá para eles terem uma noção do que que é um tronco, do que que é um casarão, o que que era um engenho... o que era a escravidão em si. (Cristiano, 2016)

Discursos de alguns documentos norteadores, que estavam para ser transformados pela Reforma e foram instituídos em um tempo em que a democracia não estava sob alerta, registravam aspectos semelhantes aos indicados por Cristiano (2016). Assim, de acordo com as Orientações Curriculares para o Ensino Médio (Brasil, 2006):

a contextualização é entendida como o trabalho de atribuir sentido e significado aos temas e aos assuntos no âmbito da vida em sociedade. Os conhecimentos produzidos pelos estudiosos da História e do ensino da História, no âmbito das universidades, por exemplo, são referências importantes para a construção dos conhecimentos escolares na dimensão da sala de aula. No entanto, é imprescindível que a seleção da narrativa histórica consagrada pela historiografia esteja relacionada aos problemas concretos que circundam os alunos das diversas escolas que compõem o sistema escolar. Para adquirir significado e possibilitar impulsos criativos, além da seleção de temas e assuntos que tenham relação com o ambiente social dos alunos, o trabalho pedagógico contará com atividades problematizadoras diante da realidade social. Dessa forma será possível articular os conhecimentos produzidos de acordo com o rigor analítico-científico do processo de conhecimento histórico ao trabalho pedagógico concreto em sala de aula. (Brasil, 2006, p. 69)

Além disso, não deixamos de considerar a condição de protagonismo de ativistas “jovens", e não "apenas" discentes de escolas públicas, sobretudo nas avaliações de como o ensino de história deveria - na visão de vários - ser.

O debate em torno das temáticas das culturas juvenis e da juventude como categoria social é fundamental para a compreensão do papel da docência em História nos tempos atuais. Provoca a olhar e escutar os jovens em suas questões, compreendendo-os como pessoas que estão às voltas com a vida, representantes de uma 
forma de viver a juventude em tempos e espaços que lhes são próprios, incita a pensar que não são sujeitos que apenas experimentam uma fase da vida que irá passar, mas vivenciam conosco, de forma peculiar, seus processos indissociáveis de constituição histórica, individual e social. A relação que estabelecemos com nossos jovens alunos é pautada pelos nossos próprios aprendizados e interrogações em relação às tensões da vida e aos conhecimentos aí produzidos. (Pereira et al., 2014, p. 164)

A condição de jovens atores não os retirou de outras dinâmicas sociais, pois muitos trabalhavam, alguns tinham filhos, outros militavam em partidos e coletivos culturais, outros cuidavam de suas próprias casas e de familiares mais velhos. Essas relações criaram certas experiências que foram levadas para as dinâmicas das ocupações de escolas. Porém, (1) não chegamos a aferir o quanto as aulas de história e de humanidades, ministradas antes das ocupações, contribuíram para elaboração de consciência social (histórica) crítica aos ocupantes. De todo modo, (2) a educação informal produzida no âmbito do contexto formal, por meio coletivo, opõe-se (se não as derruba por completo) às perspectivas a respeito de "manipulação" de jovens, aos moldes do que é pretendido pelos apoiadores do projeto Escola Sem Partido.

$\mathrm{Na}$ avaliação dos partidários de tal projeto, as "práticas de doutrinação política e ideológica",

apesar de sua manifesta inconstitucionalidade e ilegalidade, tomaram conta do sistema de ensino. A pretexto de "construir uma sociedade mais justa" ou de "combater o preconceito", professores de todos os níveis vêm utilizando o tempo precioso de suas aulas para "fazer a cabeça" dos alunos sobre questões de natureza político-partidária, ideológica e moral. (Por uma lei..., [201-])

$\mathrm{Na}$ perspectiva dos ocupantes de escolas, os quais criaram espaços de discussão sobre questões diversas, a avaliação toma caminhos totalmente distintos das ilusões dos partidários da "lei da mordaça":

Denise: [Para] finalizar, o que você espera assim da ocupação? Desse processo?

Laura: Eu espero que a gente vença essa guerra, não queremos é menores gastos é, na nossa educação, infelizmente a gente tá sofrendo um momento de crise e isso só vai piorar, a gente não quer que piora, pode até ficar desse jeito meio que 
equilibrado, mas a gente tá lutando, e a gente tá lutando pra vencer essa guerra e conseguir a meta que é acabar com a PEC, acabar com a Escola Sem Partido. Imagina uma Escola Sem Partido? É uma escola com racismo, uma escola com preconceito, é uma escola em que os alunos não têm voz. Contra a medida provisória do ensino médio, o governo tá querendo fazer tipo a gente sem filosofia, sem sociologia, sem história. A gente quer uma sabedoria a mais pra eles não passar por cima da gente. E eles não vão passar por cima da gente, a gente tá aqui, justamente por isso, pra não se passado por cima. (Laura, 2016)

Em oposição aos desmanches propiciados pelas Reformas, as ocupações deixaram um legado futuro para a transformação do ensino e das escolas. Mediante o apresentado nas narrativas que foram gravadas durante as ocupações das escolas, evidenciamos possibilidades de avaliação e reformulação de práticas de ensino atuais. As práticas educativas informais, praticadas rotineiramente durante a onda de protestos, colocaram os estudantes que delas participaram como sujeitos ativos (Arroyo, 2007) do processo de ensino e da organização curricular e escolar. Os elementos apontados por eles intuíram (e potencialmente podem ainda intuir) novas práticas e novas concepções sobre a educação por meio e por agência de toda a comunidade escolar.

\section{CONSIDERAÇÕES FINAIS}

A crítica às modificações curriculares, comuns em épocas de exceção democrática (Motta; Frigotto, 2017), faz parte do movimento de estudantes brasileiros há décadas. Nos anos 1970, a União Nacional dos Estudantes (UNE) se organizou por meio de "frentes de vanguarda" e opunha-se, entre outras questões, à criação da disciplina de Moral e Cívica (Müller, 2016).

Certamente, muitas distinções devem ser feitas entre as ações estudantis de então e as da década de 1970. A forma de organização das ocupações de escolas, mesmo que tenha se mantido em diálogo com sindicatos e grupos políticos, configura-se de forma "autonomista", contrapondo-se, de acordo com alguns documentos, à UNE de 2015 (Campos et al., 2016, p. 58).

Mas nem por isso as pautas deixaram de ser conciliadas, mesmo em contextos históricos distintos. Isso se deve, sobretudo, à postura autoritária do 
governo federal e pelo conservadorismo que emerge na sociedade brasileira em períodos de baixa da democracia.

Além da luta contra a redução do Currículo e a implantação da "Moral e Cívica", o Conselho da UNE e de outras entidades estudantis, no período da Ditadura Militar, se colocaram contra o Decreto-Lei n. 477, de 26 de fevereiro de 1969, que definiu atividades "praticadas por professores, alunos, funcionários ou empregados de estabelecimentos de ensino público ou particulares" (Brasil, 1969).

Prevendo duras penas para greves, agitação e prática de "atos destinados à organização de movimentos subversivos, passeatas, desfiles ou comícios não autorizados" (Brasil, 1969), registra as seguintes normas a serem cumpridas por professores e discentes de todos os níveis de ensino:

IV - Conduza ou realize, confeccione, imprima, tenha em depósito, distribua material subversivo de qualquer natureza;

$\mathrm{V}$ - Sequestre ou mantenha em cárcere privado diretor, membro de corpo docente, funcionário ou empregado de estabelecimento de ensino, agente de autoridade ou aluno;

VI - Use dependência ou recinto escolar para fins de subversão ou para praticar ato contrário à moral ou à ordem pública. (Brasil, 1969)

O Decreto-Lei, tido como o "AI-5 da Educação", teve efeitos práticos ao cassar, prender e expulsar vários discentes e professores de suas atuações (Motta, 2014). Durante as ocupações de 2016, os estudantes se puseram contra o Projeto Escola Sem Partido, que em muitos aspectos retoma a censura às práticas do ensinar e do aprender.

Desse modo, o projeto nacional da Escola Sem Partido foi interrompido no ano de 2018, mas a Reforma do Ensino Médio foi aprovada - em meio a inseguranças e ameaças de eliminação da obrigatoriedade de várias disciplinas, entre elas à de História. Desse modo, as ocupações de escolas, sobretudo as ocorridas em 2016, se tornaram inconclusas, pois as pautas se agudizaram e direitos sociais correm perigo. A juventude se renova, novos estudantes adentram o Ensino Básico, enquanto barreiras antidemocráticas, ao se erguerem, demonstram sinais de fissuras em suas bases. Assim, tal como indicado por Gohn (2014), mesmo não se mantendo por muito tempo, o tipo de mobilização 
empreendido mantém suas "raízes da revolta do protesto" vivas, e pode estar “prestes a explodir a qualquer momento" (Gohn, 2014, p. 440).

\section{REFERÊNCIAS}

APPLE, Michael. Ideologia e currículo. São Paulo: Brasiliense, 1982.

ARROYO, Miguel G. Currículo, território em disputa. Petrópolis: Vozes, 2013.

ARROYO, Miguel G. Educadores e educandos: seus direitos e o Currículo. In: SALTO PARA O FUTURO. Indagações sobre o currículo do Ensino Fundamental. Rio de Janeiro: TV Escola/Secretaria de Educação a Distância, Ministério da Educação, 2007. p. 17-52. (Boletim 17).

BRASIL. Decreto-Lei no 477, de 26 de fevereiro de 1969. Define infrações disciplinares praticadas por professores, alunos, funcionários ou empregados de estabelecimentos de ensino público ou particulares, e dá outras providências. Diário Oficial da União: seção 1, Brasília, DF, p. 1706, 26 fev. 1969. Disponível em: http://www2.camara.leg.br/legin/fed/declei/1960-1969/decreto-lei-477-26-fevereiro-1969-367006-publicacaooriginal-1-pe.html. Acesso em: 20 mar. 2018.

BRASIL. Orientações curriculares para o ensino médio: ciências humanas e suas tecnologias. Brasília: Ministério da Educação/Secretaria de Educação Básica/ Departamento de Políticas de Ensino Médio, 2006. v. 3. Disponível em: http://portal.mec.gov.br/seb/arquivos/pdf/book_volume_03_internet.pdf. Acesso em: 20 mar. 2018.

CAMPOS, Antonia; MEDEIROS, Jonas; RIBEIRO, Márcio. Escola de. Lutas. São Paulo: Veneta, 2016. (Coleção Baderna).

CASTORIADIS, Cornelius; COHN-BENDIT, Daniel. Da ecologia à autonomia. São Paulo: Brasiliense, 1981.

CERRI, Luís F. Saberes históricos diante da avaliação do ensino: notas sobre os conteúdos de história nas provas do Exame Nacional do Ensino Médio - ENEM. Revista Brasileira de História, São Paulo, v. 24, n. 48, p. 213-231, 2004. Disponível em: http://www.scielo.br/scielo.php?script=sci_arttext\&pid=S0102-0188200 400020 0010\#tx10. Acesso em: 20 mar. 2018.

EDITORIAL Collective. History Workshop Journal. v. 1, n. 1, 1976. Disponível em: https://academic.oup.com/hwj/article-abstract/1/1/1/557138?redirectedFrom=ful ltext. Acesso em: 20 mar. 2018.

FÁVERO, Douglas G.; DE SORDI, Denise N.; MORAIS, Sérgio P. A dimensão educativa do movimento de ocupações - o legado da pedagogia russa presente nas escolas em Uberlândia (MG). In: LUCENA, Carlos; LUCENA, Lurdes; BERNARDES, Elizabeth L. (org.). Trabalho e educação: teoria e resistência. 1. ed. 
eletrônica. Uberlândia, MG: Navegando Publicações, 2018. p. 161-182. Disponível em: https://www.editoranavegando.com/livro-dinter. Acesso em: 20 dez. 2018.

FENELON, Déa R. A formação do profissional de história e a realidade do ensino. Tempos Históricos. v. 12, n. 1, p. 23-35, 2008. Disponível em: http://e-revista.unioeste. br/index.php/temposhistoricos/article/view/1942/1534. Acesso em: 20 mar. 2018.

FERREIRA, Márcia O. V. Somos todos trabalhadores em Educação? reflexões sobre identidades docentes desde a perspectiva de sindicalistas. Educ. Pesqui. [online]. São Paulo, v. 32, n. 2, 2006. Disponível em: http://www.scielo.br/scielo.php?pid= S151797022006000200002\&script=sci_abstract\&tlng=pt. Acesso em: 20 mar. 2018.

FONSECA, Selva G. Didática e prática de ensino de História: experiências, reflexões e aprendizados. Campinas: Papirus, 2003. (Coleção Magistério: Formação e Trabalho Pedagógico).

GOHN, Maria da Glória. Jovens na política na atualidade - uma nova cultura de participação. Caderno CRH, Salvador, v. 31, n. 82, p. 117-133, 2018. Disponível em: http://www.scielo.br/pdf/ccrh/v31n82/0103-4979-ccrh-31-82-0117.pdf. Acesso em: 19 jan. 2019.

GOHN, Maria da Glória. Movimentos sociais na contemporaneidade. Revista Brasileira de Educação, v. 16, n. 47, p. 333-361, maio/ago. 2011.

GOHN, Maria da Glória. A sociedade brasileira em movimento: vozes das ruas e seus ecos políticos e sociais. Caderno CRH. Salvador, v. 27, n. 71, p. 431-441. 2014. Disponível em: http://www.scielo.br/scielo.php?pid=S0103-49792014000200013\& script=sci_abstract\&tlng=pt. Acesso em: 20 mar. 2018.

GRAMSCI, Antonio. Cadernos do cárcere. v. 2: Os Intelectuais. O princípio Educativo. Jornalismo. Edição e tradução de Carlos Nelson Coutinho; Coedição de Luiz Sérgio Henriques e Marco Aurélio Nogueira. Rio de Janeiro: Civilização Brasileira, 2000.

HARVEY, David. O direito à Cidade. Lutas Sociais, São Paulo, n. 29, p. 73-89, 2012. Disponível em: http://revistas.pucsp.br/index.php/ls/article/view/18497. Acesso em: 20 mar. 2018.

KAYE, Harvey J. The British Marxist historians. Basingstoke: Macmillan, 1995.

MARTINS, Suely A. E. P. Thompson e a educação: a socialização como experiência. Revista HISTEDBR On-line, Campinas, v. 14, n. 59, p. 304-317, 2014. Disponível em: https://periodicos.sbu.unicamp.br/ojs/index.php/histedbr/article/ view/8640365. Acesso em: 20 mar. 2018.

MARX, Karl. Crítica ao Programa de Gotha. In: ANTUNES, Ricardo (org.). A dialética do trabalho: escritos de Marx e Engels. São Paulo: Ed. Expressão Popular, 2004.

MARX, Karl. O Capital: crítica da economia política. Livro I: O processo de produção do capital. Tradução de Rubens Enderle. 2. ed. São Paulo: Boitempo, 2017. 
MORAIS, Sérgio P. Autonomia e experiências sociais: ocupações de escolas públicas na cidade de Uberlândia/MG (2016). Projeto História, São Paulo, v. 63, p. 175-204, 2018. Disponível em: https://revistas.pucsp.br/revph/article/view/40645. Acesso em: 19 jan. 2019.

MOTTA, Rodrigo P. S. As universidades e o regime militar: cultura política brasileira e modernização autoritária. Rio de Janeiro: Jorge Zahar, 2014.

MOTTA, Vânia C.; FRIGOTTO, Gaudêncio. Por que a urgência da Reforma do Ensino Médio? Medida Provisória no 746/2016 (Lei no 13.415/2017). Educação e Sociedade, Campinas, v. 38, n. 139, p. 355-372, 2017. Disponível em: http://www.scielo.br/pdf/ es/v38n139/1678-4626-es-38-139-00355.pdf. Acesso em: 20 mar. 2018.

MÜLLER, Angélica. O Movimento Estudantil na resistência à Ditadura Militar (19691979). Rio de janeiro: Garamond: Faperj, 2016.

ORTELladO, Pablo. Prefácio. A primeira flor de junho. In: CAMPOS, Antonia; MEDEIROS, Jonas; RIBEIRO, Márcio. Escola de. Lutas. São Paulo: Veneta, 2016. p. 10-16. (Coleção Baderna).

PEIXOTO, Maria do Rosário da C. Ensino como pesquisa: um novo olhar sobre a história no ensino fundamental - como e por que aprender/ensinar história. História e Perspectivas, Uberlândia, v. 28, n. 53, p. 37-70, 2015. Disponível em: http://www.seer.ufu.br/index.php/historiaperspectivas/article/view/32765. Acesso em: 20 mar. 2019.

PEREIRA, Nilton M.; SEFNER, Fernando; ZELI, Carmem; MEINERZ, Carla. Docência em História: implicações das novas disposições curriculares do ensino médio. Rev. Bras. Estud. Pedag. [online]. Brasília, v. 95, n. 239, p. 152-174, 2014. Disponível em: http://www.scielo.br/scielo.php?pid=S2176-66812014000100009 \&script=sci_abstract\&tlng=pt. Acesso em: 20 mar. 2018.

PORTELLI, Alessandro. A Filosofia e os fatos. Revista Tempo, Rio de Janeiro, v. 1, n. 2, p. 59-72, 1996.

POR UMA LEI contra o abuso da liberdade de ensinar. Escola Sem Partido. O Projeto. [201-]. Disponível em: https://www.programaescolasempartido.org/projeto. Acesso em: 19 jan. 2019.

RICCI, Rudá G. M. S. As ocupações estudantes de 2016: a transformação do território chamado escola. Blog do Rudá. 2018. Disponível em: http://www.rudaricci.com.br/ as-ocupacoes-estudantes-de-2016-a-transformacao-do-territorio-chamado-escola/. Acesso em: 3 maio 2018.

ROLNIK, Raquel. Guerra dos lugares: a colonização da terra e da moradia na era das finanças. São Paulo: Boitempo, 2015.

SHARPE, Jim. A história vista de baixo. In: BURKE, Peter (org.). A escrita da história: novas perspectivas. São Paulo: Ed. Unesp, 1992. p. 39-62. 
SOUZA, Alana M. Contato e improvisação: o que pode querer dizer autonomia? Cadernos IHU - Instituto Humanitas Unisinos, São Leopoldo, v. 16, n. 268, p. 1-20, 2018. Disponível em: http://www.ihu.unisinos.br/images/stories/cadernos/ ideias/268cadernosihuideias.pdf. Acesso em: 8 jan. 2019.

THOMPSON, Edward P. A miséria da teoria ou um planetário de erros: uma crítica ao pensamento de Althusser. Tradução de Waltensir Dutra. Rio de Janeiro: Jorge Zahar, 1981.

THOMPSON, Edward P. Educação e experiência. In: THOMPSON, Edward P. Os românticos: a Inglaterra na era revolucionária. Tradução de Sérgio Moraes Rêgo Reis. Rio de Janeiro: Civilização Brasileira, 2002.

THOMPSON, Edward P. Folclore, antropologia e história social. In: THOMPSON, Edward P. As peculiaridades dos ingleses e outros artigos. Organização de Antonio Luigi Negro e Sergio Silva. 2. ed. Campinas: Ed. Unicamp, 2012.

WILLIS, Paul. Aprendendo a ser trabalhador: escola, resistência e reprodução social. Tradução de Tomaz Tadeu da Silva e Daise Batista. Porto Alegre: Artes Médicas, 1991.

ZIBAS, Dagmar M. L. Refundar o ensino médio? Alguns antecedentes e atuais desdobramentos das políticas dos anos de 1990. Educação \& Sociedade, Campinas, v. 26, n. 92, p. 1067-1086, 2005. Disponível em: http://www.scielo.br/scielo.php?script= sci_arttext\&pid=S0101-73302005000300016\&lng=en\&nrm=iso\&tlng=pt. Acesso em: 20 mar. 2018.

Entrevistas

ALICE. Escola Estadual Jerônimo Arantes, Uberlândia (MG). 2 nov. 2016. Entrevista realizada por Denise Nunes De Sordi. Acervo de pesquisa.

CARLA. Escola Estadual Neuza Rezende, Uberlândia (MG). 2 nov. 2016. Entrevista realizada por Denise Nunes De Sordi. Acervo de pesquisa.

CRISTIANO. Escola Estadual Sérgio de Freitas Pacheco, Uberlândia (MG). 30 out. 2016. Entrevista realizada por Denise Nunes De Sordi. Acervo de pesquisa.

JULIANA. Escola Estadual Neuza Rezende, Uberlândia (MG). 2 nov. 2016. Entrevista realizada por Denise Nunes De Sordi. Acervo de pesquisa.

LAURA. Escola Estadual Prof. Juvenília Ferreira dos Santos, Uberlândia (MG). 29 out. 2016. Entrevista realizada por Denise Nunes De Sordi. Acervo de pesquisa.

LUCAS, Escola Estadual Jerônimo Arantes, Uberlândia (MG). 2 nov. 2016. Entrevista realizada por Denise Nunes De Sordi. Acervo de pesquisa.

MELINA. Escola Estadual de Uberlândia (Museu), Uberlândia (MG). 31 out. 2016. Entrevista realizada por Denise Nunes De Sordi. Acervo de pesquisa.

TIAGO, Escola Estadual Teotônio Vilela, Uberlândia (MG). 31 out. 2016. Entrevista realizada por Denise Nunes De Sordi. Acervo de pesquisa. 


\section{NOTAS}

${ }^{1}$ Pesquisa apoiada por Fapemig, CHE - APQ-02063-17, CNPq (CNPq/409878/2018-9), projeto: "Ensino Formal e Programa Bolsa Escola Federal: experiências, vivências e interpretações de assistidos na cidade de Uberlândia MG" e pelo Edital Fundação de Apoio Universitário (FAU) da Universidade Federal de Uberlândia (FAU/UFU - Edital 002/2018).

${ }^{2}$ A PEC n ${ }^{\circ} 241$, aprovada no dia 13 dez. 2016 e que congelou os gastos do governo pelos próximos 20 anos, também ficou conhecida, entre a oposição, como "PEC do fim do mundo", "PEC da morte" ou, entre a situação, "PEC do teto". A Medida Provisória n 746, popularmente conhecida como Reforma do Ensino Médio, refere-se ao projeto - já aprovado - de recomposição dos principais eixos do atual modelo de educação formal. O Projeto de Lei no 193/2016, conhecido também por "Lei da Mordaça", inclui o programa Escola sem Partido entre as diretrizes da educação formal nacional e declara ter por objetivo combater a doutrinação política e ideológica em sala de aula e garantir o ensino moral e religioso.

${ }^{3}$ Foram entrevistados 15 estudantes de seis escolas diferentes agrupadas em 12 entrevistas, realizadas mediante termo de ciência e autorização pelos estudantes maiores de idade ou seus responsáveis. As entrevistas foram produzidas a partir de perguntas semiestruturadas em temas comuns, possibilitando que os estudantes desenvolvessem suas narrativas sem interrupções, permitindo que apreendêssemos opiniões de ativistas de distintas configurações socioeconômicas, de diferentes bairros, turnos e escolas sobre um processo de organização política vivido em comum. Ainda, em busca de garantir o sigilo dos estudantes entrevistados, todos os nomes utilizados são fictícios. Essas entrevistas foram realizadas por componentes do Grupo de Pesquisa Experiências e Processos Sociais (GPEPS/CNPq/ UFU), e compõem acervo e discussão teórica provenientes dos seguintes projetos: "História Social e História oral: pesquisas sobre trabalho e trabalhadores no Triângulo Mineiro (2000-2016)", com financiamento da Fundação de Amparo à Pesquisa do Estado Minas Gerais (Fapemig/APQ - 02063-17); "Ensino Formal e Programa Bolsa Escola Federal - experiências, vivências e interpretações de assistidos na cidade de Uberlândia MG", com financiamento do Conselho Nacional de Desenvolvimento Científico e Tecnológico (CNPq) (CNPq/409878/2018-9), e Edital Fundação de Apoio Universitário (FAU) da Universidade Federal de Uberlândia (FAU/UFU - Edital 002/2018).

${ }^{4}$ Algumas narrativas que demonstram a existência do que aqui discutimos encontram-se em Morais (2018).

Artigo recebido em 2 de abril de 2018. Aprovado em 26 de junho de 2019. 